\title{
Complex Vesicovaginal Fistula Repair with Gracilis Muscle Interposition Flap - Case Series of 5 Patients and Review of Literature
}

\section{Sharma A*, Chaudhari R, Shaikh I, Desai R, Andankar M and Pathak H}

Department of Urology, TNMC \& BYL Nair Hospital, Mumbai 400008, Maharashtra, India

*Corresponding author: Sharma A, Resident, Department of Urology, TNMC \& BYL Nair Hospital, Mumbai, Maharashtra, India, E-mail: dramiturology@gmail.com

Citation: Sharma A, Chaudhari R, Shaikh I, Andankar M, Pathak H, et al. (2014) Complex Vesicovaginal Fistula Repair with Gracilis Muscle Interposition Flap - Case Series of 5 Patients and Review of Literature. J Case Rep Stud 2(6): 604. doi: 10.15744/2348-9820.2.304

Received Date: October 17, 2014 Accepted Date: December 03, 2014 Published Date: December 05, 2014

\section{Abstract}

Complex Vescico-vaginal Fistulas (VVF) are a common cause of morbidity especially in elderly patients. These can be one of the most troublesome complications of obstetric trauma and pelvic surgery and usually occur due to previous operative interventions and/or as a result of chronic diseases. These are difficult to repair because of the poor or almost no supporting tissue left at the perineum as a result of the previous insults. According to the principles of fistula closures, some form of vascular tissue should be applied as a graft for the successful repair of these complex fistulas. Despite many advances in the medical field, repair of complex VVF continues to present a major technical challenge for modern surgery. We achieved this by using Gracilis muscle interposition flap for repair of these complex VVFs.

Keywords: Complex Vescico-vaginal Fistula; Gracilis Flap; Ischaemia; Recurrent Fistula

\section{Introduction}

Complex vesicovaginal fistulas (VVF) are those size $>1 \mathrm{~cm}$ and associated with poor tissue quality due to ischemia, recurrent fistula, associated with other injuries of ureter, colon, rectum, urethra and those post-malignancy, post-radiation. These can be very challenging to repair, simple closures usually leading to recurrences and often requiring interposition of well-vascularized tissue between the urinary bladder and vagina. The first description of such a successful repair of vesicovaginal fistulas (VVFs) dates back to Sims' classic work in 1852, which reported a successful operation by using silver sutures and bladder drainage in a slave after several failed attempts [1].

We present our experience using gracilis muscle interposition flap for complex vesicovaginal fistula repair in 5 patients (Figure 1).

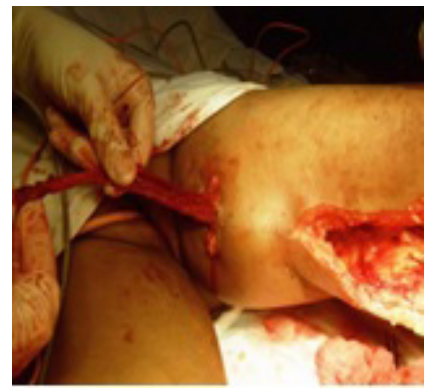

\section{Materials and Methods}

Figure 1: Mobilized gracilis muscle flap through the subcutaneous tunnel

A retrospective analysis was performed to identify patients who had undergone VVF repair with Gracilis interposition flap from Aug 2012 to Aug 2013. Data of 5 patients (this being a tertiary institute, these cases were referred from other centres) were collected focusing on preoperative patient characteristics, etiology of VVF, investigation, intraoperative parameters, including surgical techniques and postoperative patient outcomes (Figure 2).

\section{Results}

Gracilis muscle interposition flap was used in 5 patients for VVF repair. Three of these patients were between 40 to 60 years of age and had abdominal hysterectomy done and all had single large fistula of $1.5 \mathrm{~cm}$ to $2.5 \mathrm{~cm}$ near bladder neck communicating with the anterior vaginal wall. Two of these had undergone failed repair of their fistulas. The remaining 2 patients were between 25 to 30 years of age and the Vescico-vaginal Fistula had developed after prolonged obstructed labour and both of them had recurrence after failed repair. Both had single large fistula of $2 \mathrm{~cm}$ to $3 \mathrm{~cm}$ on posterior bladder wall in subtrigonal area extending through bladder neck and urethra (Figure 3 and 4). 




Figure 2: Intra operative planning for gracilis muscle flap: incision taken as shown, Gracilis muscle identified and disconnected from its distal insertion while preserving the blood supply

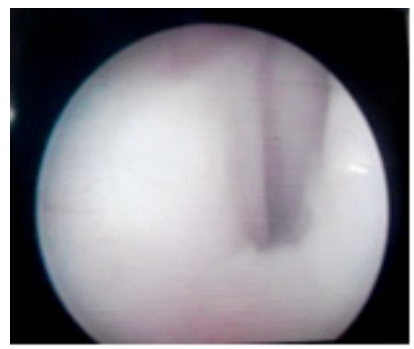

Figure 3

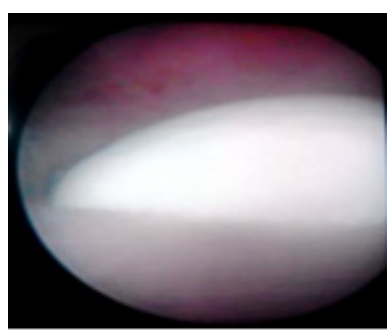

Figure 4

Figure 3 and 4: Cystoscopic view showing a large vesicovaginal fistula at trigonal area

Investigation included Intravenous Urography (IVU), cystoscopy, vaginoscopy and examination under anesthesia. Abdominal approach was not used as all the patients had undergone some surgery in the past. Intra-operatively, first the patients were placed in prone jack-knife position and after separating the vaginal wall from urethra and bladder neck, the urethral and bladder margins were freshened and sutured in midline with delayed absorbable suture. A layer of paravescical tissue was also approximated in the midline. Then the patient was placed in supine position, left Gracilis muscle was harvested- a medial incision of about $20 \mathrm{~cm}$ in length was taken $10 \mathrm{~cm}$ below the pubic tubercle on left thigh; the muscle was disconnected at its distal insertion and mobilized proximally upto $8 \mathrm{~cm}$ to $10 \mathrm{~cm}$ from pubic tubercle. The pedicle of the muscle was preserved during this procedure. A tunnel was then created underneath the medial aspect of thigh and labia and the flap was thus transferred to the vaginal area. Now the patient was placed in lithotomy position, the harvested Gracilis muscle was placed and sutured over the repaired bladder and paravescical tissue in overlapping fashion between the raised vaginal flaps which were then approximated over it.

The average intra-operative time was 3 hours and blood loss was approximately $100 \mathrm{ml}$ to $150 \mathrm{ml}$. A trans-vaginal pack was kept which was removed after 24 hours. All patients had smooth post-operative outcome. Patients were kept catheterized for 3 weeks. They were given intravenous antibiotics for 2 days and discharged on post-operative day 3 on oral antibiotics for 7 days. Anticholinergic drugs were given to 2 patients who had symptoms of bladder irritation. Catheter was removed after 3 weeks. At 3 month follow-up, one patient developed urine leak; on cystoscopy she had urethral loss which is awaiting urethral reconstruction. Rest all are doing well on follow-up and have no complaints.

\section{Discussion}

Several surgical procedures for repair of complex fistulas between the bladder and the urethra or vagina have been reported. Commonly used are the Martius graft (labial fibro-fatty graft) [2], omental graft [3], peritoneal flap [4], muscle interposition flaps like sartorius [5], rectus abdominis [6], adductor magnus [7] and gracilis. In our study, we used the gracilis muscle interposition flap in repairing these complex VVF. The gracilis muscle is a thin strap-like muscle in the adductor compartment of the thigh and has good blood supply. It was first used to treat an intractable urethrovescico-vaginal fistula in 1928 by Garlock [5].

All our 5 patients managed by this flap had an uneventful post-operative course. Only one patient developed urinary leak within 3 months of follow-up due to urethral loss (success rate 80\%). All the others are doing well and have no complaints. 
There are many reports in Literature on the use of gracilis muscle interposition flap for the repair of VVFs. Ingelman-Sundberg used this muscle by negotiating it through a perforation in the obturator membrane [7]. Nicholson and Hamlin tunneled the reflected gracilis muscle subcutaneously from the apex of the thigh incision to the fistula site [8]. The same technique was followed in our institute for these 5 patients.

Fleishmann and Picha used this technique in the abdominal repair of these fistulas by transferring the muscle through the space of Retzius and penetrating the endopelvic fascia [9]. Heckler et al. [10] repaired complex fistulas in children using this muscle. Nowadays, overlying cutaneous islands are being used to close the large defects [11].

Thus to sum up, the use of gracilis muscle interposition flap is associated with minimal morbidity and a high success rate [12,13]. It is an excellent option for patients with complicated fistulas for whom other surgical treatments have failed [14].

\section{Conclusion}

Complex vesicovaginal fistula typically require tissue interposition and can be successfully repaired with gracilis muscle interposition flap at first attempt and well suited for VVF lying at bladder neck or trigone or just above trigone.

\section{Acknowledgement}

To the Department of Plastic Surgery, TNMC and BYL Nair Hospital for their expert advice and guidance during the initial cases in harvesting the Gracilis muscle flap.

\section{References}

1. Sims JM (1852) On the treatment of vesicovaginal fistulas. Am J Med Sci 45: 59-82.

2. Elkins TE, DeLancey JO, McGuire EJ (1990) The use of modified Martius graft as an adjunctive technique in vesicovaginal and rectovaginal fistula repair. Obstet Gynecol 75: 727-33.

3. Wein AJ, Malloy TR, Greenberg SH, Carpiniello VL, Murphy JJ (1980) Omental transposition as an aid in genitourinary reconstructive procedures. J Trauma 20: 473-7.

4. Poderatz KC (1987) Vesicovaginal fistulae. Monaghan JM (ed) Rob and Smith's Operative Surgery: obstetrics and gynaecology (4 $4^{\text {th }}$ edn), London: Butterworths 127-142.

5. Garlock JH (1928) The cure of an intractable vesicovaginal fistula by use of a pedicled muscle graft. Surg Gynecol Obstet 47: 255-60.

6. Menacha A, Akhyat M, Gleicher N (1990) The rectus abdominis muscle flap in a combined abdominovaginal repair for difficult vesicovaginal fistulae: a report of 3 cases. J Reprod Med 35: 565-8.

7. Ingelman-Sundberg A (1960) Pathogenesias and operative treatment of urinary fistulas in irradiated tissue: Youssef AF Gynecology urology. Springfield, Ill: Charles C Thomas 263-79.

8. Hamlin RH, Nicholson EC (1969) Reconstruction of urethra totally destroyed in labour. Br Med J 2: 147-50.

9. Fleishman J, Picha G (1988) Abdominal approach for gracilis muscle interposition and repair of recurrent vesicovaginal fistulas. J Urol 140: 552-4.

10. Heckler WC, Holschneider AM, Kraeft H (1980) Der operative Verschluss recto-vaginaler, rectourethraler, urethro-vaginaler und vesico-cutaner Fistelndurch Interposition des Musculus gracilis. Chirug 51: 43-5

11. Heckler FR, Aldridge JE, Songcharoen S, Jabaley ME (1980) Muscle flaps and musculocutaneous flaps in the repair of urinary fistulas. Plastic Reconstr Surg 66: 94-101.

12. Ayed M, El Atat R, Hassine LB, Sfaxi M, Chebil M, et al. (2006) Prognostic factors of recurrence after vesicovaginal fistula repair. Int J Urol 13: $345-9$

13. Zacharin RF (1980) Grafting as a principle in the surgical management of vesicovaginal and rectovaginal fistulae. Aust N Z J Obstet Gynaecol 20: 10-7.

14. Leach GE, Trockman BA (1998) Surgery for vesicovaginal and urethrovaginal fistula and urethral diverticulum, Campbell's Urology ( $7^{\text {th }}$ edn) WB Saunders, Philadelphia 1135-53. 